\title{
MODIFICATION OF STRUCTURE AND PROPERTIES OF SURFACE LAYER OF GREY CAST IRON UNDER HIGH ENERGY ELECTRON BEAM
}

\author{
N.M. Alexandrova, S.Yu. Mackushev \\ Institute of Physical Metallurgy, Moscow 107005, Russia \\ AND V.E. MeLnikov \\ Serp\&Molot Co. Ltd, Moscow 109033, Russia
}

\begin{abstract}
The effect of high energy electron beam irradiation on the crystalline structure and mechanical properties of the surface layer of grey cast iron has been investigated by light and electron microscopy, X-ray analysis as well as microhardness measurements. The electron irradiation leads to the formation of modulated structure of the surface layer, which provides the combination of the high hardness level and the high wear resistance. These properties are caused by the high density of the structural defects in austenite phase, the formation of the high number of dispersed carbides and the existence of a set of phases from ledeburite till sorbite with high level of hardness.
\end{abstract}

PACS numbers: $62.90 .+\mathrm{k}, 68.45 . \mathrm{Nj}$

\section{Introduction and experimental}

Grey cast iron with carbon content $C \approx 3 \%$ is applied for making up some details of the metallurgical equipment, for instance guides for the high temperature wire rolling equipment operated at heavy conditions. These guides are subjected to the abrasive wear and to the dynamic loading because of the high speed of the wire movement. The lack of now existing guides from the as-cast grey iron is their low wear resistance [1]. In order to avoid this lack, it is necessary to use the methods of the initial structure modification, at first turn the methods of surface hardening. Among them one of the most effective one is the method of the irradiation by high energy electron beam, which allows to get the complex of physical and mechanical properties, which is impossible to reach by the use of traditional methods.

This paper is devoted to the investigation of the electron irradiation influence on the structure and properties of grey cast iron guides of the grade wire rolling machine 320/250 (metallurgical plant Serp\&Molot). The irradiation was performed 
on the industrial electron accelerator ELV-4, which generates continuous electron beams with energy $E=1.5 \mathrm{MeV}$, power up to $50 \mathrm{~kW}$ and treats the surface metal layers up to $1 \mathrm{~mm}$ and more [2].

The structure of the initial and irradiated material was investigated by light and electron microscopy methods as well as by X-ray analysis using Fe-irradiation. The mechanical properties of the surface layers were controlled by microhardness measurements.

\section{Experimental results and discussion}

After irradiation the surface layers of the guides consist of the alternating zones:

— irradiated - smelted off one;

- transition - zone of the thermal influence;

- parent grey cast iron matrix.

In Fig. 1 there are the results of the microhardness investigation along the sample length. The microhardness testing shows that the HV increases from 180 for the grey cast matrix till 820 for the irradiated zone. The analysis of the microstructure of the parent grey cast iron shows that the latter one consists of pearlite with microhardness $\mathrm{HV}=220$, ferrite with microhardness 80 and laminar graphite (Fig. 2a). Under electron beam action local metal heating up to the melting point and following fast cooling because of the intensive heat flow into the bulk of the material take place. It leads to crystallization processes developing in the irradiated zone and corresponding phase transformations in accordance with $\mathrm{Fe}-\mathrm{C}$ phase diagram. In that case we observe the formation of the ledeburite eutectics (Fig. 2b) with very high level of microhardness in the irradiated (smelled off) layer. The region of the ledeburite eutetics is propagated on the depth till $180 \mu \mathrm{m}$. In the transition zone the partial dissolution of the graphite inclusions is observed. Around the graphite plates we can notice the ledeburite with the thin layers of the retained austenite formation. On the place of the former pearlite colonies

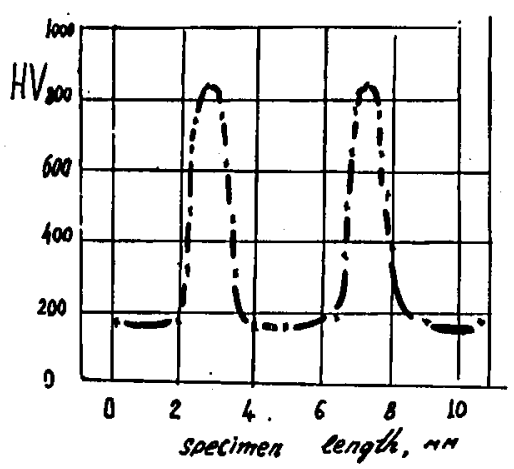

Fig. 1. Microhardness changes along the length of the irradiated sample. 

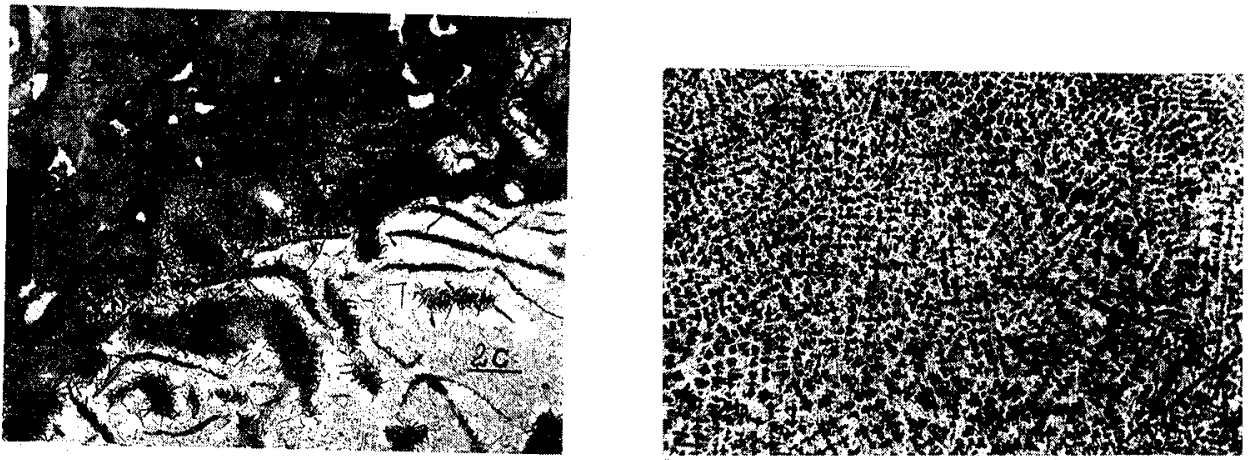

Fig. 2. Microstructure of the surface of the irradiated grey cast iron: (a) initial structure, (b) irradiated zone $\times 400,(c)$ transition zone $\times 400$.

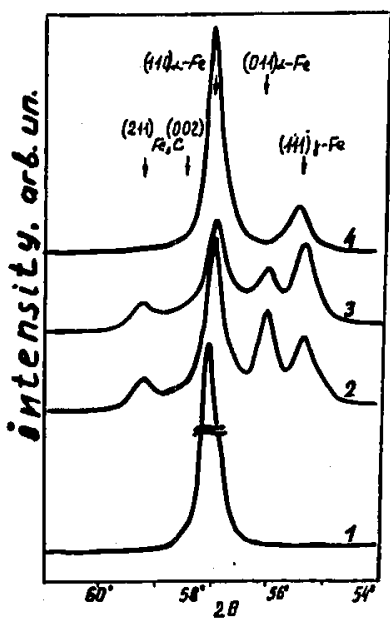

Fig. 3. X-ray diffraction pattern of the initial (1) and irradiated (2-4) samples.

the zones of martensite $(\mathrm{HV}=720)$, troostite with $\mathrm{HV}=430$ and sorbite with $\mathrm{HV}=320$ occur. These zones are in contact with the retained austenite partially penetrated by martensite needles (Fig. 2c).

It is necessary to note that there is no sharp boundary between the hardened zone and the initial structure.

These results are in good agreement with the $\mathrm{X}$-ray diffraction data. On the $\mathrm{X}$-ray diffraction pattern of the initial grey cast iron there are sharp reflexes of the bcc $\alpha$-Fe lattice only (Fig. 3). The reflexes of the carbide phase have not been observed because of small volume fracture and disperse character of the latter one. At the same time the diffraction pattern of the irradiated material is modified essentially (Fig. 3, curves 2-4). The pronounced tetragonal doublet (110), (011) of the $\alpha$-martensite BCT-lattice appears on the diffraction pattern. The value of the tetragonal distortion is $c / a=1.039$, which corresponds to the carbon content in 


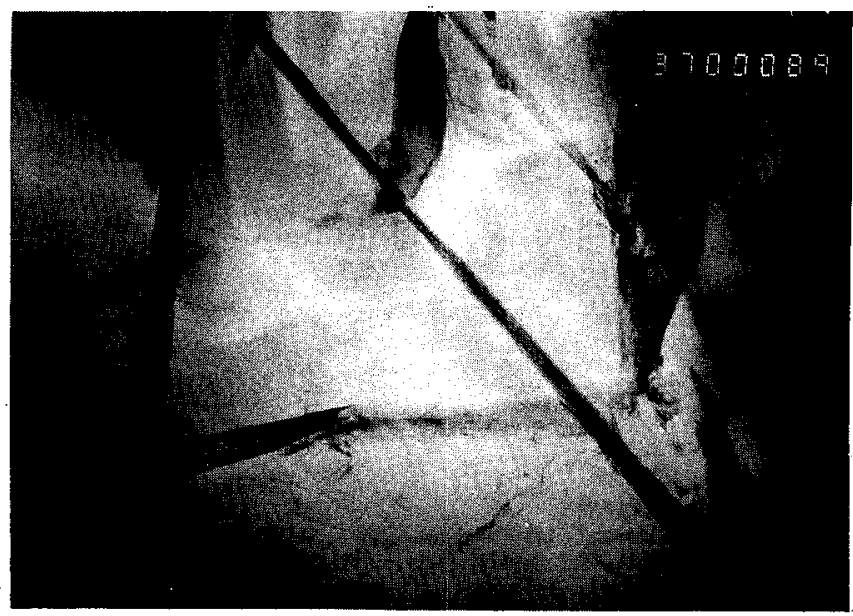

Fig. 4. Electron microscope images of the structure of irradiated sample $(\times 37000)$.

the martensite $0.9-1.0 \%$. Additionally, the reflexes of the retained austenite (volume fracture is about $35-37 \%$ ), which has an increasing carbon content, and $\mathrm{Fe}_{3} \mathrm{C}$ carbide phase appear. It is evident that upon the irradiation the smelt gains the enrichment by carbon because of graphite dissolution, and the ledeburite eutectics with big amount of cementite is formed. At further cooling the austenite undergoes partial transformation into the high carbon content martensite. In the transition zone the martensitic reaction also takes place, but according to X-ray data the carbon content in martensite is much lower (no more than $0.3-0.4 \%$ ) and retained austenite fracture is about $25 \%$. The particularities of the crystalline structure of the austenite in the irradiated samples have been investigated by transmission electron microscopy. In Fig. 4 one can see a typical structure of the samples surface layers. There is retained austenite, which penetrates by separated large martensite crystals. The special feature of austenite is high density of stacking faults, microtwins and dislocations. It can be supposed that these defects appear as a result of the deformation induced in the process of martensitic transformation.

\section{Conclusions}

1. Electron beam irradiation of the guides from grey cast iron leads to modulated structure creation which provides the combination of the high hardness level and high wear resistance.

2. These properties are caused by the high density of the crystalline structure defects in austenite phase, the formation of the big number of dispersed carbides and existence of the set of high-hardened structure components from ledeburite till sorbite.

3. Operating tests of the electron-irradiation treated guides on the hot rolling machine 320/250 upon grade steel rolling show the increase in wear resistance at least by $2-2.5$ times. The electron beam treatment allows also to reduce the rolling 
efforts because of graphite modifications, operating as a lubricant for high-temperature rolling.

\section{References}

[1] N.M. Alexandrova, G.V. Sherbedinskij, V.N. Lazarev, I.N. Meshkov, V.P. Nekipelov, Met. Sci. Heat Treat. 3, 10 (1991).

[2] N.M. Dovgij, S.S. Klyagin, I.E. Pavlenko, M.V. Dubin, Chyornaya Metallurgia 18, 45 (1985). 